\title{
TECHNICAL ANALYSIS OF FULL-SCALE CONSTRUCTION AND DEMOLITION WASTE TREATMENT PLANTS: CASE STUDIES OF THE LOMBARDY REGION, ITALY
}

\author{
Alessandra Diotti *, Giovanni Plizzari and Sabrina Sorlini
}

Department of Civil Engineering, Architecture, Land, Environment and Mathematics, University of Brescia, via Branze 43, 25123 Brescia, Italy

Article Info:

Received:

30 July 2020

Revised:

4 March 2021

Accepted:

15 March 2021

Available online:

6 June 2021

Keywords:

CDW

Recycled Aggregate

CDW treatment chains

CDW management

Chemical characterization

Total chromium

\begin{abstract}
Construction and demolition activities in Italy and the Lombardy Region produce a considerable amount of wastes that can be valorised as secondary raw materials. The recovery of construction and demolition wastes is severely limited by the lack of consolidated and sustainable treatment chains and by the strong variability of their environmental characteristics that may generate potentially dangerous effects for the environment. The purpose of this study was to evaluate and technically define the current treatment chains in the Province of Brescia (Lombardy) by analyzing three full-scale treatment plants in order to highlight barriers to demolition waste recovery and propose possible solutions and improvement strategies. To best represent the entire management and treatment system, the analysis was developed on all the acceptance, treatment, and final quality control phases. Moreover, chemical composition and leaching data on demolition wastes and recycled aggregates were collected from the three treatment plants and statistically analyzed to assess their potential recovery according to the Italian legislation. Mixed non-hazardous waste is the fraction mostly managed by recycling plants and mixed recycled aggregates are the main products obtained from the treatment. These are mostly used in roads and in geotechnical applications. Chemical composition results showed that the $\mathrm{pH}$ is generally alkaline and tin and benzene are the most critical elements for both demolition wastes and recycled aggregates with respect to the regulatory limit values. Total chromium was identified as a critical compound in leachates. The results of the statistical analysis confirmed that chromium was mainly released by cement materials.
\end{abstract}

\section{INTRODUCTION}

Construction and demolition activities produce large quantities of waste materials, called Construction and Demolition Wastes (CDWs), classified as special waste according to the current Italian legislation (Legislative Decree n. 152, 2006) and codified by Chapter 17 of the European Waste Codes (EWC). In 2016, the total wastes generated by the construction sector in Europe (EU) accounted for around $36 \%$ of the total waste production, with 924 million tons (Eurostat, 2019). Italy, with a production of about 54.5 million tons and a per-capita production of 0.9 tons, is the fourth European country for CDW production after France, Germany, and the Netherlands.

The level of EU recycling varies significantly between the Member States: from 10\% (e.g. Greece) to $90 \%$ (e.g. Germany, the Netherlands) (Giorgi et al., 2018). In Italy conflicting data on recovery rates are reported: from $10 \%$ (Legambiente, 2017) to 75\% (ISPRA, 2019).
In the Lombardy Region (northern Italy) about 12.2 million tons of CDWs were produced in 2016, which represent $41 \%$ of all special wastes produced in the region (29.4 million tons) (ISPRA, 2019). Regarding the recovery, 16.5 million tons of CDWs were treated in the region: $73 \%$ were recovered through $\mathrm{R} 5$ (recovery of inorganic substances) operations, $14 \%$ were recovered through R4 (metal recovery) operations, $5 \%$ were recovered throughother operations, while $8 \%$ were disposed of in landfills (Lombardy Region, 2018).

The interest in CDW recovery is supported by both European (Directive EU 2018/851) and Italian (L.D. 152/2006) legislations, which aim to improve the efficiency of resource recovery (e.g. any operation the principal result of which is waste serving a useful purpose by replacing other materials which would otherwise have been used to fulfil a particular function, or waste being prepared to fulfil that function, in the plant or in the wider economy) as well as 
to facilitate the transition to a more sustainable material management and to a circular economy model. In particular, the Directive EU 2018/851 requires that at least $70 \%$ of the non-hazardous CDWs produced must be recycled/recovered by 2020 . As a consequence, the sustainable CDW management and recovery has become a topic of debates at the national and regional level (Goh, 2016).

Generally, CDWs represent a large source of secondary raw materials, consisting roughly of concrete, wood, masonry, drywall, glass, plastics, metals and more (Bianchini et al., 2020; European Commission, 2017). The composition is therefore extremely variable and heterogeneous. This is mainly due to: the non-selective demolition techniques generally applied by breakers, to the lack of advanced treatment processes for recycled aggregate (RA) production, as well as to the high variability of materials used for building's construction (Ruggeri et al., 2019; Siddique \& Cachim, 2018). Based on these considerations, over $90 \%$ of CDWs produced in Italy derive from non-selective microdemolition operations of the residential and non-residential building stock (i.e. maintenance and/ or renovation works) and this significantly increases the overall CDW heterogeneity. Conversely, only $8 \%$ comes from entire building demolition (Altamura, 2015). As a result, RAs are mainly used in downcycling practices, i.e. recycling of waste in cases where the recycled product is of a lower quality than the original ones.

In the Lombardy Region, CDWs are mainly treated in dedicated mobile plants that carry out rough treatments, such as single crushing and optional screening. As stated by Borghi et al. (2018), 86.1\% of CDWs is treated in mobile plants, while only $13.9 \%$ of CDWs is sent to fixed plants. The resulting RAs have, therefore, extremely variable physical and chemical characteristics that often do not comply with the national environmental standards (Ministerial Decree n. 186, 2006) required for their use as unbound aggregates in the construction sector. In particular, in terms of contaminant release, chromium and sulphates are the most critical compounds in CDW and RA leachates (Butera et al., 2014; Galvín et al., 2014). Specifically, total chromium is mainly released by ceramic materials and partly carbonated samples, while high sulphate levels are released by gypsum-based materials and other CDW compounds (e.g. mortar particles) (Barbudo et al., 2012; López-Uceda et al., 2019; C. S. Vieira \& Pereira, 2018).

In this context, only a few studies have been developed on the in-depth analysis of the Lombard CDW treatment chains (Borghi et al., 2018; Pantini et al., 2019; Pantini \& Rigamonti, 2016). The authors of these studies have assessed the environmental impacts of the Lombard CDW management system, by applying the Life Cycle Assessment methodology, to improve the environmental performance of the current system. Conversely, literature studies on the CDW treatment chains of the Province of Brescia (the biggest Lombardy province) have not been developed so far.

Hence, the aim of this paper was to operationally define the current CDW recovery and treatment chains of the Province by analyzing 3 selected recycling plants (geographically representing the whole province). In particular, based on the observed plant behaviour, the main purpose of this technical analysis was to highlight barriers and hurdles (logistical, economic and regulatory) that still limit the recovery of CDWs and the RA end-use and to propose possible solutions and improvement strategies.

The importance of this study stems from the fact that the CDW recovery is a common concern in many Member States (e.g. Spain, Greece etc.). At the European level, this issue is addressed through the development of guidelines that aim to support national authorities in achieving the EU target for CDW recycling (European Commission, 2016). In this context, the knowledge of real case studies regarding the experiences implemented by the treatment plants as well as the obstacles still present can certainly provide an important contribution to the identification of new strategies and policy instruments by national authorities applicable at a national and international level.

Finally, since the CDW heterogeneity and the treatment techniques adopted have a significant influence on the characteristics of the final recycled materials, the present work aims also to evaluate the technical (EC marking) and environmental properties of these materials. In particular, to identify possible correlations between RA characteristics and CDWs, data on chemical and leaching properties of both CDWs and RAs were collected from the databases of the three selected CDW treatment plants and then elaborated using a statistical approach.

\section{MATERIALS AND METHODS}

\subsection{CDW treatment plants}

Three authorized treatment plants, located in the Province of Brescia (the Lombardy Region - northern Italy), were analysed to study the CDW treatment system currently adopted. These plants, called treatment plant 1 (TP1), 2 (TP2) and 3 (TP3), are in natural aggregate excavation quarries and, over time, have adapted their technologies to the treatment and recovery of CDWs. In particular, in order to evaluate a situation as representative as possible of the regional reality, TP1 and TP3 are representative of mobile treatment plants, whilst TP2 is representative of a fixed treatment plant. As stated by Borghi et al. (2018), these are the two main recycling plant categories present in the regional territory.

Differently from TP2 and TP3, respectively located in the municipalities of Manerbio and Breno, TP1 manages four plants located in the neighboring municipalities of Brescia, hereinafter called:

- TP1, : treatment plant located in the municipality of Berlingo;

- TP1, : treatment plant located in the municipality of Orzivecchi;

- TP1, : treatment plant located in the municipality of Leno;

- TP1, : storage plant located in the municipality of Poncarale (active since 2017). This plant is authorized for only CDW storage. The accepted CDWs must be subsequently sent to the above-mentioned treatment plants $\left(\mathrm{TP} 1_{1,2,3}\right)$. 
TABLE 1: EWC codes authorized and processed by the treatment plants.

\begin{tabular}{|c|c|c|c|c|c|c|}
\hline \multirow{2}{*}{\multicolumn{2}{|c|}{$\begin{array}{l}\text { CDW treatment } \\
\text { plant }\end{array}$}} & \multirow{2}{*}{ Type } & \multirow{2}{*}{ Common authorized EWC codes } & \multirow{2}{*}{ Additional EWC codes } & \multicolumn{2}{|c|}{ Authorized operations } \\
\hline & & & & & $\mathbf{R} 13\left(\mathrm{~m}^{3}\right)$ & R5 (t/y) \\
\hline TP1 & $\begin{array}{l}\text { TP1 } \\
\text { TP1, } \\
\text { TP1, } \\
\text { TP1, } \\
\end{array}$ & Mobile & \multirow{3}{*}{$\begin{array}{l}170101 \text { - concrete } \\
170102 \text { - bricks } \\
170103 \text { - tiles and ceramics } \\
170107 \text { - mixtures of concrete, bricks, tiles and ceramics } \\
170504 \text { - soil and stones } \\
170802 \text { - gypsum-based construction materials } \\
170904 \text { - mixed construction and demolition wastes }\end{array}$} & - & $\begin{array}{l}3,300 \\
1,750 \\
2,211 \\
2,700\end{array}$ & $\begin{array}{c}107,000 \\
55,000 \\
90,000 \\
-\end{array}$ \\
\hline \multicolumn{2}{|c|}{ TP2 } & Fixed & & 170508 - track ballast & 1,584 & 55,000 \\
\hline \multicolumn{2}{|c|}{ TP3 } & Mobile & & 170302 - bituminous mixtures & 2,650 & 101,600 \\
\hline
\end{tabular}

R5: recycling/reclamation of other inorganic materials

R13: storage of wastes pending any of the operations numbered $R 1$ to R12, excluding temporary storage, pending collection, on the site where it is produced

All the treatment plants are authorized to process and manage only non-hazardous CDWs with EWC codes of chapter 17, as shown in Table 1.

From CDW treatment, RAs of different quality and grain size are produced.

\subsection{Data collection}

In order to best represent the CDW treatment chains currently operating in the Province of Brescia, the following historic data were acquired and collected from the three treatment plants analyzed.

\subsubsection{CDW and RA flows}

In order to evaluate the amount of CDWs managed and RAs produced by the three treatment plants, the following data were extracted and collected from the databases of the TP companies, on a yearly basis: total quantity of incoming CDWs, quantity of incoming CDWs according to EWC codes of Chapter 17 and, finally, quantity or RAs produced. In particular, the annual amount of CDWs entering the treatment plants was assessed by analysing the annual mandatory declaration (i.e Environmental Declaration Model - calld MUD in Italy) submitted by treatment operators to the territorially competent Chamber of Commerce, in accordance with Article 189 of L.D. 152/2006.

A six-year reference period was used for data collection (from 2013 to 2018). In this way, it was possible to set up the mass balance of the entire CDW management system of the 3 recycling plants.

At the same time, based on the acquired flow data, the current recovery efficiency of the treatment plants and the performances of their treatment systems was also assessed (i.e. ratio between the quantities of CDWs treated and RAs produced).

2.2.2 Quality control procedures carried out on incoming CDWs and outgoing RAs and treatment processes and technologies adopted

In this section, in order to technically outline the current CDW management and treatment systems, primary information and operational-management data were collected during technical visits performed at 3 recycling plants. The main goal was to identify the recovery solutions already applied in the region and the workflows implemented by recycling plants for CDW treatment and RA production.

Based on the requirements imposed by all 3 plant authorizations, data about CDWs acceptance and manage- ment criteria were firstly acquired. Subsequently, field visits were performed to gather information about the treatment processes and technologies adopted, as well as the type and actual end-uses of RAs produced. Moreover, the quality control systems implemented in the production of RAs were identified, based on both technical standards and environmental compatibility requirements.

\subsubsection{Technical and environmental properties of both CDWs and RAs}

To statistically evaluate the technical and environmental behaviour of CDWs and RAs, several certificates of EC marking, chemical characterization and leaching tests were provided by the 3 treatment plants and by the Italian Lombardy Builders' Association (ANCE Lombardy) and the National Association of Recycled Aggregate Producers (ANPAR).

All the certificates refer to a collection time period of 10 years. Over 1,400 certificates were collected in pdf format and subsequently reworked in digital format. Of these, 46 were related to EC marking, 865 certificates were related to chemical analyses and 535 related to leaching tests, divided as reported in Table 2. In particular, as regulated by the Italian Environmental Legislation (L.D. 152/2006 and M.D. 186/2006), chemical analyses refer to the CDW non-hazardousness assessment performed by the CDW owner (breaker) before sending the CDWs to the treatment plants, whilst the leaching tests refer to the RAs eco-compatibility assessment.

The leaching tests were performed according to the compliance test imposed by UNI EN 12457-2:2004. The procedure consists of a one stage batch leaching test at a liquid to solid ratio of $10 \mathrm{~L} / \mathrm{kg}$ applied to materials with a particle size below $4 \mathrm{~mm}$.

All the collected data were then processed and elabo-

TABLE 2: Number of certificates of EC marking, chemical analysis and leaching test in relation to TPs and material analyzed.

\begin{tabular}{|c|c|c|c|c|c|c|}
\hline Certificates & Sample & TP1 & TP2 & TP3 & Others ${ }^{(1)}$ & Total \\
\hline \multirow{2}{*}{$\begin{array}{l}\text { Chemical } \\
\text { analysis }\end{array}$} & CDWs & 140 & 342 & 283 & 14 & 779 \\
\hline & RAs & 0 & 33 & 52 & 1 & 86 \\
\hline \multirow{2}{*}{$\begin{array}{l}\text { Leaching } \\
\text { tests }\end{array}$} & CDWs & 15 & 165 & 35 & 35 & 250 \\
\hline & RAs & 134 & 31 & 98 & 22 & 285 \\
\hline EC marking & RAs & 3 & 3 & 40 & - & 46 \\
\hline
\end{tabular}

(1) ANCE Lombardy and ANPAR databases. 
rated using the statistical software "IBM SPSS 19.0" in order to identify the variability ranges of chemical and leaching characteristics of both CDWs and RAs, as well as the potential critical parameters for recovery under the Italian national legislation (L.D. 152/2006 and M.D. 186/2006). In particular, for CDWs, reference was made to the codes generally most received by the treatment plants: EWC 170904 "mixed CDWs", 170504 "soil and stones" and 170101 "cement" (detailed data reporting most treated CDW flows are presented in subsection 3.1). In this paper, the technical, chemical and leaching properties have been discussed in tabular format, but the release of contaminants has also been discussed by analyzing, with the box plot and violin plot methodology, two of the most critical parameters for CDW recovery: $\mathrm{pH}$ and total chromium.

\subsubsection{Economic performance of the treatment plants}

To identify the difference in economic performance between fixed and mobile systems, the data relating to energy consumption per tonne of RA produced were collected and compared.

\subsection{Statistical analysis of chemical and leaching certificates}

\subsubsection{Box-plot and violin plot methodology}

The box-plot method was applied for the processing of statistical data. This method is a useful way to visualize differences among samples or groups and it provides a lot of statistical information, including median, range and outliers, which help to better understand sample characteristics.

The box-plot divides the data sample into quartiles, as shown in Figure 1. The central part of the box-plot consists of a "box", which goes from the first quartile (Q1 - $25^{\circ}$ percentile) to the third quartile (Q3 $-75^{\circ}$ percentile). Inside the box there is the median of the data set (Q2 - 50th percentile). Half of the data values are less than the median and the other half are greater than the median. Approximately 50 percent of all data fall inside the box (interquartile range IQR).
The lower and upper extremes, graphically represented by a line that goes out from the box to more or less 1.5 IQR (whiskers), represent the maximum and minimum values of the data set that are not outliers or extreme values. The whiskers show the range between these two extremes. A larger range indicates a wider distribution, i.e. more scattered data.

Points outside the whisker boundaries are anomalous values considered as outliers and/or extreme values. These values are very small or large and can affect the overall observation made from the data series. Outliers are all the values that lie from 1.5 to 3 times IQR (marked with circles beyond the whiskers), whilst extreme values lie more than 3 times IQR (marked with asterisks beyond the whiskers).

In the present study, the box-plots were used to graphically reproduce the variability and the dispersion of the various pollutant concentrations present within the data population with reference to the leaching tests performed on CDWs and RAs.

For better data representation, the same data were also elaborated and graphically represented by means of the violin plots. Unlike the box-plot, however similar, the violin plot allows to detect, with its "violin" shape, the density variation of the analyzed data, as shown in Figure 2.

\section{RESULTS AND DISCUSSION}

\subsection{CDW and RA flows}

Results from flow data elaboration are presented in Table 3. In the reference period, about 1.3 Mt of CDWs were managed by the three treatment plants. The results show that TP1 managed and treated the largest amount of CDWs equal to over $60 \%$ of all CDWs managed by the 3 treatment plants, while TP2 and TP3 manage approximately 20\% respectively.

The average recovery efficiency, calculated as the ratio between the quantities of RAs produced and CDWs treated, varies considerably according to the technology adopted by the plant. The fixed plant (TP2), equipped with performing technologies, has the highest recovery efficiency

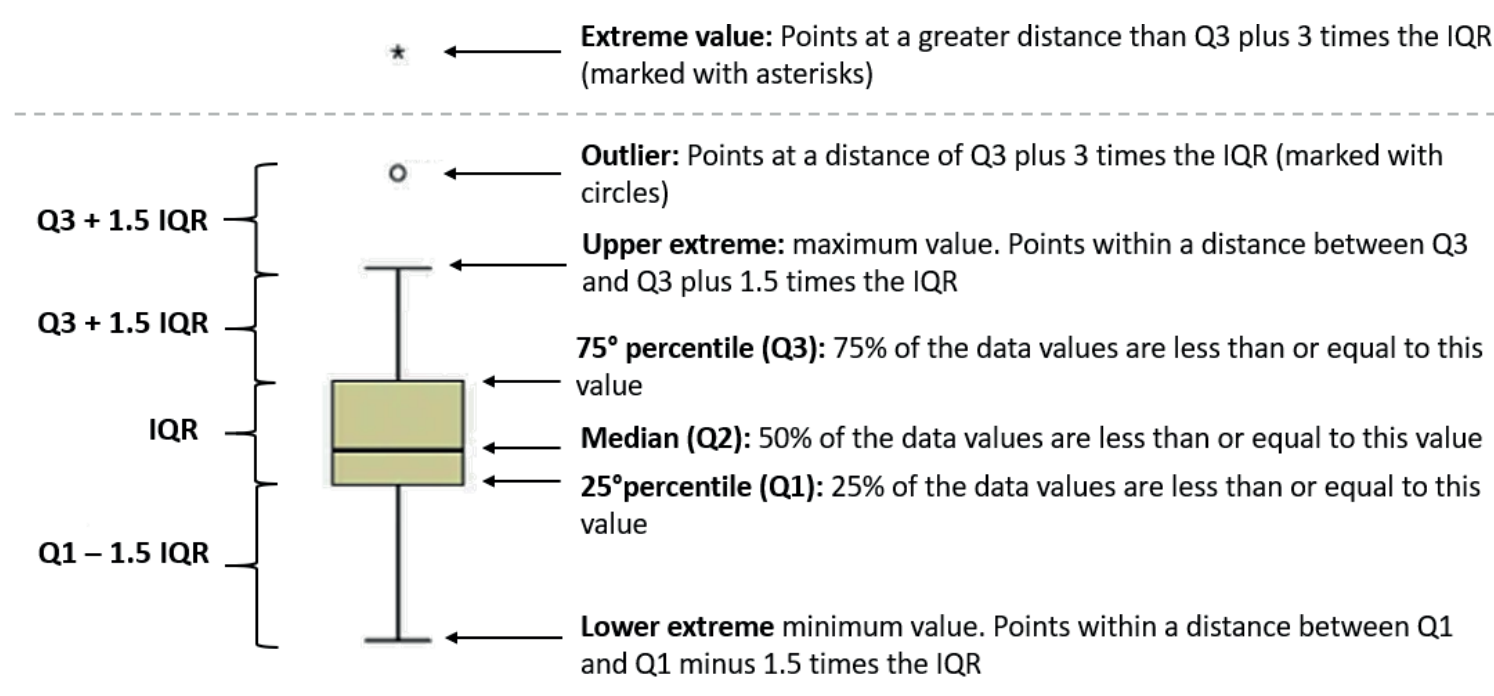

FIGURE 1: Structure of the box-plot chart. 


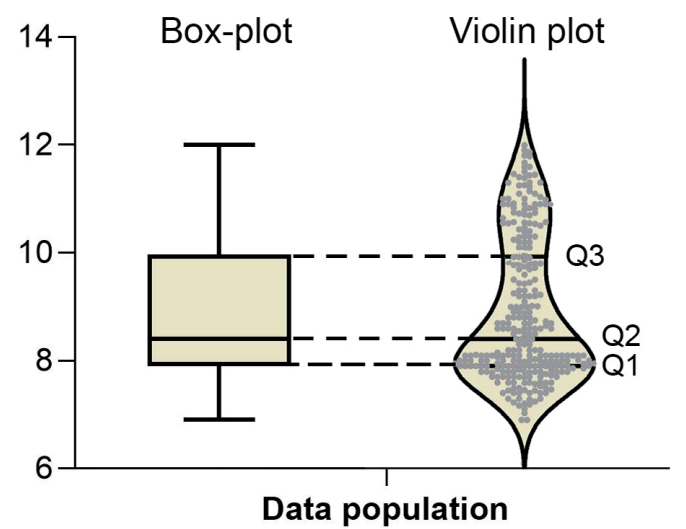

FIGURE 2: Structure of the violin plot chart.

of $95 \%$. On the other hand, mobile plants (TP1 and TP3), equipped with less performing technologies compared to fixed plants, have lower efficiencies of $62 \%$ and $70 \%$ respectively.

As reported in Figure 3, the mixed construction and demolition waste (EWC 170904) is the main flow managed by the TPs, accounting for approximately $50 \%-80 \%$. In accordance with the national situation, the CDWs delivered to the plants mainly derive from microdemolition operations of the residential building stock. In these activities, selective demolition is almost absent and, therefore, the CDWs produced are highly heterogeneous and classified as mixed construction and demolition wastes.

Soil and stones (EWC 170504) are the second most managed CDW stream, with about $11 \%-36 \%$. This type of waste mainly derives from excavation works (i.e. removal of rocks and/or soils for new building construction or for existing building extension).

Finally, cement (EWC 170101) is the third most managed and treated flow, equal to $7 \%-14 \%$ of the total CDW amount. It mainly comes from the demolition of prefabricated industrial buildings.

At the same time, mixture of concrete, bricks, tiles and ceramics (EWC 170107), bituminous mixtures (EWC 170302) and track ballast (EWC 170508) are the least managed flows (less than 3\%). All the other authorized EWC codes are delivered to TPs in quantities slightly greater than $0 \%$.
TABLE 3: CDWs managed and RAs produced by the three TPS (from 2013 to 2018) and TP's recovery efficiency.

\begin{tabular}{|c|c|c|c|c|}
\hline \multicolumn{2}{|c|}{ Treatment plant } & \multirow{2}{*}{$\begin{array}{c}\text { Total CDWs } \\
\text { managed (t) } \\
486,295 \\
233,059 \\
98,167 \\
6,369\end{array}$} & \multirow{2}{*}{$\begin{array}{c}\text { RAs produced } \\
\text { (t) }\end{array}$} & \multirow{2}{*}{$\begin{array}{c}\begin{array}{c}\text { TP recovery } \\
\text { efficiency (\%) }\end{array} \\
62\end{array}$} \\
\hline TP1 & $\begin{array}{l}\text { TP1 } \\
\text { TP1 }_{1,} \\
\text { TP1 }{ }^{2}, \\
\text { TP1 }_{1,4}\end{array}$ & & & \\
\hline \multicolumn{2}{|c|}{ TP2 } & 238,650 & 231,340 & 95 \\
\hline \multicolumn{2}{|c|}{ TP3 } & 229,915 & 160,580 & 70 \\
\hline \multicolumn{2}{|c|}{ Total } & 1292,455 & 909,8 & \\
\hline
\end{tabular}

\subsection{CDW treatment chains}

\subsubsection{CDW acceptance and management criteria}

At the entrance to each treatment plant (TP1, TP2 and TP3), CDWs are subjected to acceptance procedures carried out by the following consecutive operations:

- Acquisition of the Waste Identification Form (called FIR in Italy): according to L.D. 152/2006, the CDW owner is obliged to trace the flows of CDWs produced in all transport phases, from the production site to the treatment plant. In this form the owner identifies the amount of CDWs produced, their EWC codes, the demolition building site and all the data of breaker, transporter and recipient (treatment plant).

- First visual inspection of incoming CDWs on trucks (by digital cameras) in order to verify the conformity of the material supplied to the plant with what was declared in the waste identification form.

- Assessment of CDW non-hazardousness by acquiring the chemical characterization analysis from the CDW owner. This operation is carried out so that the treatment plants are authorized to receive only non-hazardous CDWs.

The chemical parameters that must be analyzed by the producer are identified by accredited laboratories in relation to the type of CDWs and the local context in which the plant operates. In particular, for mixed construction and demolition waste (EWC 170904) the presence of asbestos must be detected.

Similarly, for CDWs identified by EWC codes 170302 "bituminous mixtures" (received by TP3) and 170508 "track ballast" (received by TP2), the PAH content and the ophiolite stone content $(<0.1 \%$ by mass) must be respectively
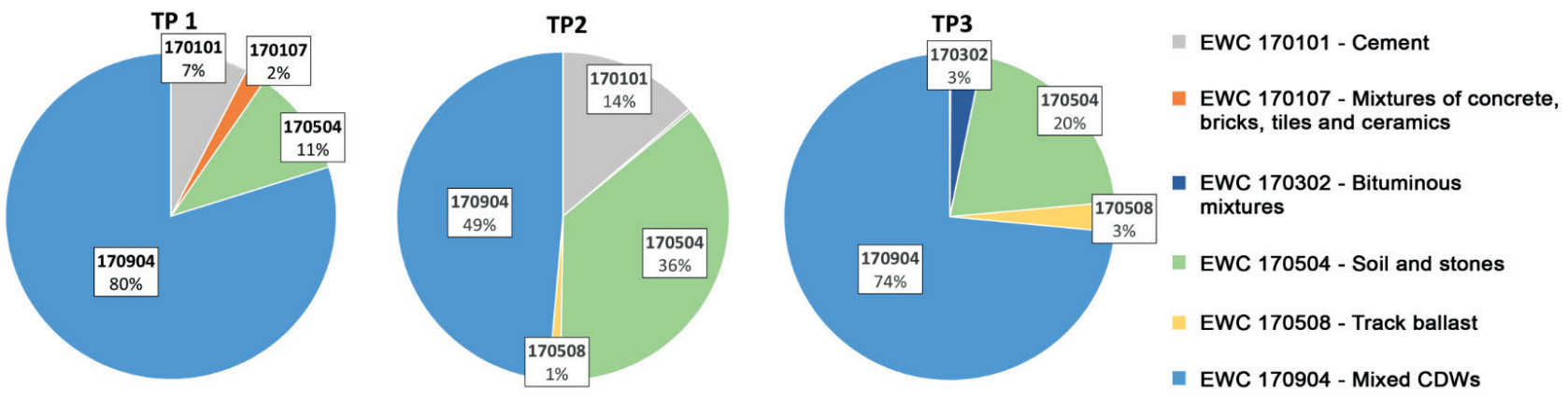

FIGURE 3: Type of CDWs mostly managed by the three TPs in the reference period (2013-2018). 
detected. In particular, the ophiolite stone is a green rock, generally used for the construction of roads and railway sub-base layers, which can naturally contain asbestos fibers.

All these preliminary operations must be performed by the treatment plant for each CDW reception.

Only in the case that CDWs come from private microdemolition (limited to EWC 170904) or from a well-defined and known technological cycle (sole producer), can the analytical non-hazardousness evaluation be performed by the treatment plant, respectively, every 6 months or when 500 $\mathrm{m}^{3}$ of CDWs are reached. If non-compliance is determined on the heaps, the material must be sent to authorized disposal plants.

In any case, if the material does not comply with all the three above-mentioned conditions, the load is rejected. Conversely, the CDWs that are accepted must be weighed and stored on paved areas, according to EWC codes (R13 operation). This operation is mandatory and required by the plant environmental authorization to guarantee the traceability of the managed CDW flows. In this way, the inspection body in case of environmental non-compliance can trace the load of non-compliant material.

During the discharge in the storage areas, an additional visual quality control is performed to remove any unwanted coarse materials that cannot be treated by the system. Finally, all the CDWs stored using R13 recovery operation must end up in the final treatment process within 6 months of acceptance.

\subsubsection{CDW treatment process}

After the storage, the CDWs are sent to the mechanical treatment process, as shown in Figure 4. All 3 treatment plants have a single treatment line from which mixed recycled aggregates (MRAs) are obtained.

In the pre-treatment phase, the CDWs are fed to the treatment system by means of a crawler excavator, and the different EWC codes are mixed together. As confirmed by Borghi et al. (2018), the most common practice applied in the region is to mix them to obtain MRAs. This process is implemented since the market demand is exclusively directed to low-level applications (road and geotechnical ap-

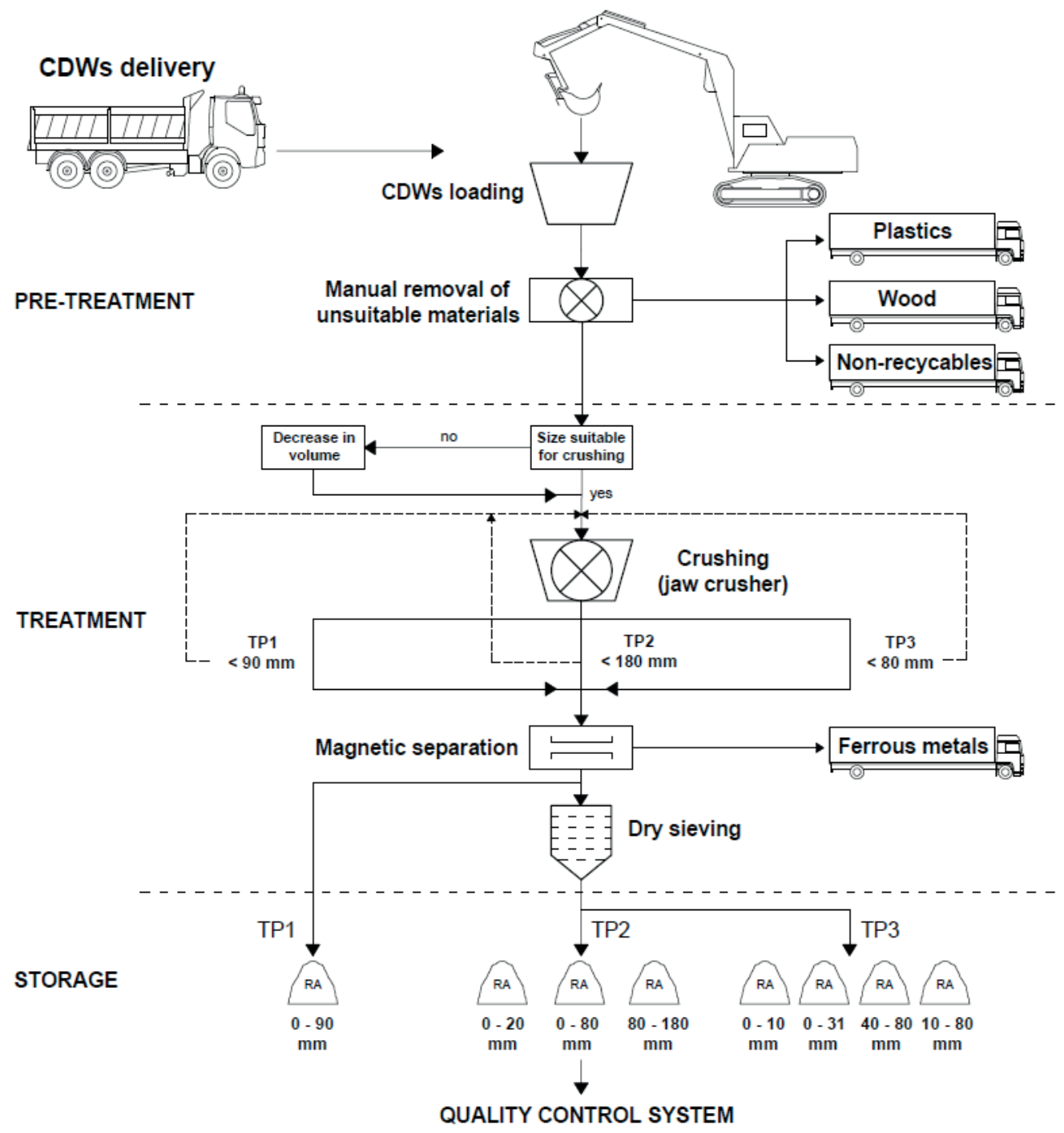

FIGURE 4: CDW treatment flow sheet. 
plications) where MRAs are required. Treatment plants are therefore not incentivized to implement their own technologies for better-quality RA production which would require high economic costs. Moreover, this homogenization process is linked to the need to guarantee the environmental compliance of the RAs produced by reducing the pollutant concentrations. As shown in paragraph 3.3.2, some EWC codes contain high pollutant concentrations which, if treated individually, can generate RAs that do not comply with national environmental requirements (e.g. EWC 170101 "cement" releases high amounts of chromium or EWC 170802 "gypsum" releases sulphates).

At the same time, all the impurities (plastics, wood, glass, non recyclables fractions, etc.) are manually removed by operators and collected in roll-off containers to obtain final quality RAs. These wastes must be identified by EWC code 19 and then destined to authorized recovery or disposal plants.

In the subsequent treatment phase, according to the treatment plant analysed, the material is crushed by a jaw crusher to different maximum grain sizes (D):

- $\mathrm{D}<90 \mathrm{~mm}$ in TP1;

- $\mathrm{D}<180 \mathrm{~mm}$ in TP2;

- $\mathrm{D}<80 \mathrm{~mm}$ in TP3.

The oversize fraction (higher than $90 \mathrm{~mm}, 180 \mathrm{~mm}$ and $80 \mathrm{~mm}$ ) is reprocessed in the crusher to further decrease the particle volume. Instead, the large CDW elements (Figure 5) that cannot be directly sent to the crushing phase are previously reduced in size using hammers and demolition grapples.

After crushing, in order to separate and remove all ferrous metals, the material is sent to the deferrization phase consisting of a powerful electromagnetic iron remover placed perpendicular to the treated material flow. The removed ferrous metals, coded with EWC 191001 "iron and steel waste", are deposited in a roll-off container and subsequently destined to authorized recovery plants.

After volumetric reduction and deferrization, the materials processed in TP1 are stored as RAs, while the materials processed in TP2 and TP3 are sent to the sieving phase. In particular, before being sent to the screening phase, as

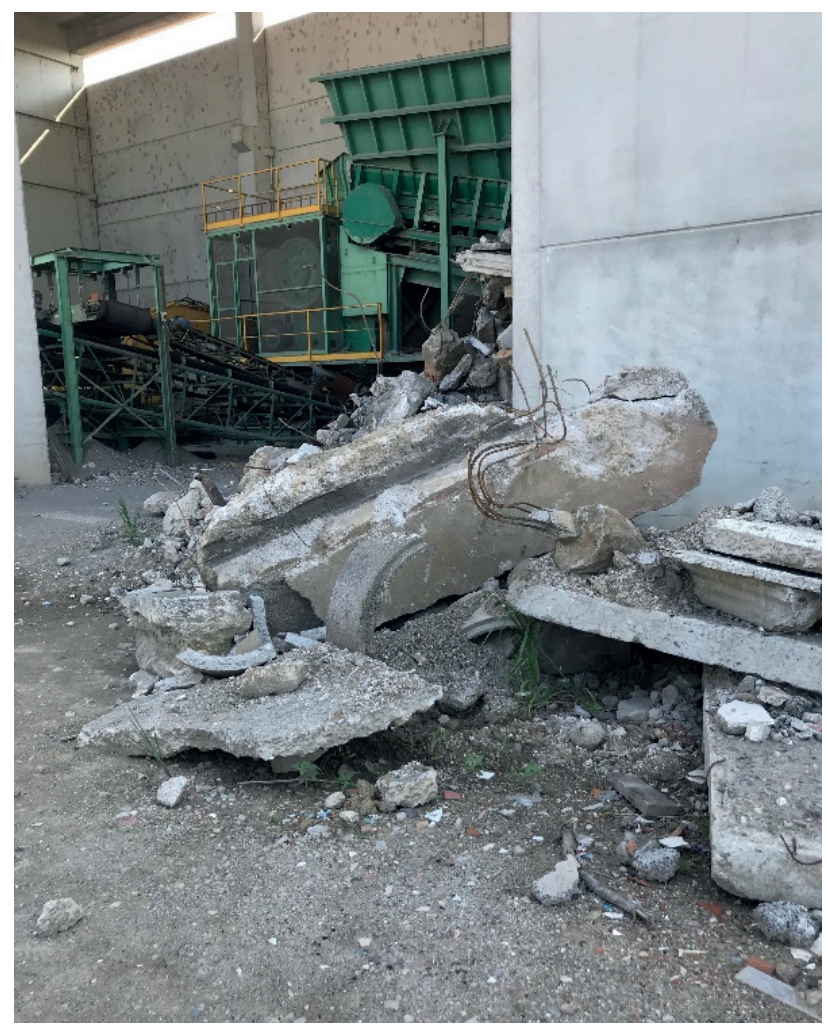

FIGURE 5: CDW large elements with unsuitable size for direct crushing.

specified by the granted authorization, the material processed in TP2 must be subjected to leaching test (every $15 \mathrm{~m}^{3}$ ), according to EN 12457-2. If the material complies with the national environmental regulatory limits (M.D. $186 / 2006)$, it can be sent to the sieving phase. Otherwise, it must be sent to authorized disposal plants.

A dry sieve, with one or several sizes according to the end-user's demand, is used for granulometric selection and different type of RAs (all-in, fine, medium, and coarse fractions) are obtained in the 3 treatment plants, as shown in Table 4. In particular, to avoid the formation of dust during the sieving phase, water sprinklers and nebulizers are used.

TABLE 4: Type and grain size of RAs produced by the 3 treatment plants.

\begin{tabular}{|c|c|c|c|}
\hline Treatment plant & RA type & Grain size (mm) & Uses \\
\hline TP1 & All-in & $0-90$ & $\begin{array}{l}\text { Road and railway embankments and sub-base layers, civil/industrial yard foundation and sub- } \\
\text { base layers, backfillings, remodeling works }\end{array}$ \\
\hline \multirow{3}{*}{ TP2 } & Fine & $0-20$ & Pipe coverings, environmental restoration \\
\hline & All-in & $0-80$ & $\begin{array}{l}\text { Road and railway embankments and sub-base layers, civil/industrial yard foundation and sub- } \\
\text { base layers, backfillings, remodeling works }\end{array}$ \\
\hline & Highly coarse & $80-180$ & $\begin{array}{l}\text { Drainage systems, reinforcement of embankment layers (built on earthy, sandy and clayey } \\
\text { ground) }\end{array}$ \\
\hline \multirow{4}{*}{ TP3 } & Fine & $0-10$ & Pipe coverings, environmental restoration \\
\hline & Medium & $0-31$ & \multirow{3}{*}{$\begin{array}{l}\text { Road and railway embankments and sub-base layers, civil/industrial yard foundation and sub- } \\
\text { base layers, backfillings, remodeling works }\end{array}$} \\
\hline & Coarse & $40-80$ & \\
\hline & Medium-coarse & $10-80^{(1)}$ & \\
\hline
\end{tabular}

(1) grain size obtained by mixing medium (0-31 $\mathrm{mm})$ and coarse $(40-80 \mathrm{~mm}) \mathrm{RAs}$. 
The fine RAs (0-10 $\mathrm{mm}$ and 0-20 $\mathrm{mm})$ are generally used for pipe coverings and environmental restoration works (i.e revitalization of depleted quarries and/or landfills).

The medium and coarse RAs $(0-31 \mathrm{~mm}, 10-80 \mathrm{~mm}$ and $40-80 \mathrm{~mm})$, as well as the all-in fractions $(0-80 \mathrm{~mm}$ and 0-90 $\mathrm{mm}$ ) are mainly used for the construction of road and railway foundations, embankments and sub-base layers, the construction of civil and industrial yard foundations and sub-base layers, as well as for backfilling applications and remodelling works.

Finally, the highly coarse RAs $(80-180 \mathrm{~mm})$ are typically used for drainage layers and for the reinforcement of embankment layers built on earthy, sandy and clayey soils.

In the case that the end-user requests a selected grain size, RAs are reprocessed to obtain the required particle size.

As stated before, the RAs produced by the 3 TPs are MRAs currently used in low-grade applications.

In 2019, TP1 experimentally produced recycled concrete aggregates (RCAs) for internal use in concrete production. Unfortunately, at the regional and national level, there is no market demand for RCAs and, therefore, the company has stopped its production without future application developments.

Finally, according to the particle size, the RAs produced are stored in heaps located on natural draining surfaces. In particular, to avoid the dispersion of dust, an anemometer is positioned above the RA heaps to activate the wetting system if the wind speed exceeds $3 \mathrm{~m} / \mathrm{s}$. In case of wind above $10 \mathrm{~m} / \mathrm{s}$, the treatment process must be stopped.

\subsubsection{RA quality control procedures}

At the end of the entire treatment line, the RAs produced by the 3 TPs are subjected to a technical and environmental quality control system.

Since there are no national End of Waste criteria for CDWs in Italy, the RAs produced must be subjected to leaching test according to EN 10802:2013 (sampling procedure) and EN 12457-2:2004 ( $\mathrm{d}<4 \mathrm{~mm}$; L/S=10 L/kg; contact time $=24 \mathrm{~h}$; demineralized water). Subsequently, the environmental compliance must be assessed with respect to the regulatory limit values of M.D. 186/2006. Based on the respective authorization, the TPs analyzed must verify the RA ecocompatibility on heaps of $1,000 \mathrm{~m}^{3}$ (TP1), $15 \mathrm{~m}^{3}$ (TP2) and 3,000 $\mathrm{m}^{3}$ (TP3), for each grain size produced.

For both domestically and abroad marketing, RAs are subsequently subjected to EC marking according to EN 13242:2008 for their use in civil engineering work and road construction. If the RAs produced by the treatment process do not comply with the above technical standards, the material must be reprocessed or, if this operation is economically or technically unsustainable, sent to authorized recovery/disposal plants.

As required by the plant authorization, in addition to EC marking and leaching test, the RAs produced by TP2 and used for backfilling or remodeling applications must also be subjected to chemical characterization test and must fall whithin the limits indicated in column A or B, Table 1, Part IV, Title V, Annex 5 of the Italian Environmental Code (L.D. 152/2006). This legislation defines the Contamination
Threshold Concentrations (CSC) in relation to soil use. Column A concerns green public areas and sites for residential use, while column $B$ refers to commercial and industrial sites.

\subsubsection{Economic performance evaluation of CDW treatment} plants

Fixed and mobile treatment plants run on different types of power. As confirmed by studies in the literature (Borghi et al., 2018), TP1 and TP3 (mobile plants) are diesel-powered, while TP2 (stationary plant) is grid connected. Generally, the fixed treatment plants have a high operational efficiency and have more advanced and performing technologies than mobile plants (e.g. optimized crushing steps, more powerful magnets, vibrating screens for different grain size production). These plants commonly provide better quality RAs. Mobile treatment plants, typically diesel-fuelled, have the great advantage of lower operating and transport costs but they usually do not apply technologically advanced treatments (simple crushing steps followed by ferrous metal separation; the sieving phase is optionally adopted). These plants generally deliver low-quality RAs classified as all-in aggregates (i.e. mixture of coarse and fine aggregates).

To evaluate the economic performance of the treatment plants, Table 5 shows the diesel/energy consumption per tonne of RAs produced. As evidenced by the results, the stationary plant uses less energy than mobile plants. As shown in Figure 6, TP2 exploits $57 \%-71 \%$ less energy than TP1 and TP3, respectively.

This difference in consumption strongly affects the technical-economic performance of mobile plants which, without a clear market demand for RAs, are not incentivized to improve the quality of the RAs produced by implementing new advanced treatment technologies. But this is not only a critical issue for mobile systems as even the fixed system, without a market demand that requires quality RAs, is not motivated to implement its own technologies.

A more refined and advanced treatment process (more crushing steps, greater particle size separation, etc.) requires very high economic costs (in the processing, logistics and handling phases) which, to date, in Lombardy and Italy are not compensated by the market demand which still favors the use of natural aggregates.

\subsection{Environmental and technical compatibility of CDWs and RAs}

Besides the analysis on CDW and RA flows and the treatment chains currently available in the Porvince of Brescia, the present work includes a statistical evaluation of the environmental performance (chemical and leaching

TABLE 5: TP consumption per tonne of RAs produced.

\begin{tabular}{l|c:cccc}
$\begin{array}{l}\text { Treatment } \\
\text { plant }\end{array}$ & Typology & $\begin{array}{l}\text { Power } \\
\text { supply }\end{array}$ & \multicolumn{1}{c}{ Consumption } \\
\hline TP1 & Mobile & Diesel & 0.225 & 0.292 \\
\hdashline TP2 & Fixed & Electricity & - & 0.125 \\
\hdashline TP3 & Mobile & Diesel & 0.333 & 0.432 \\
\hline
\end{tabular}




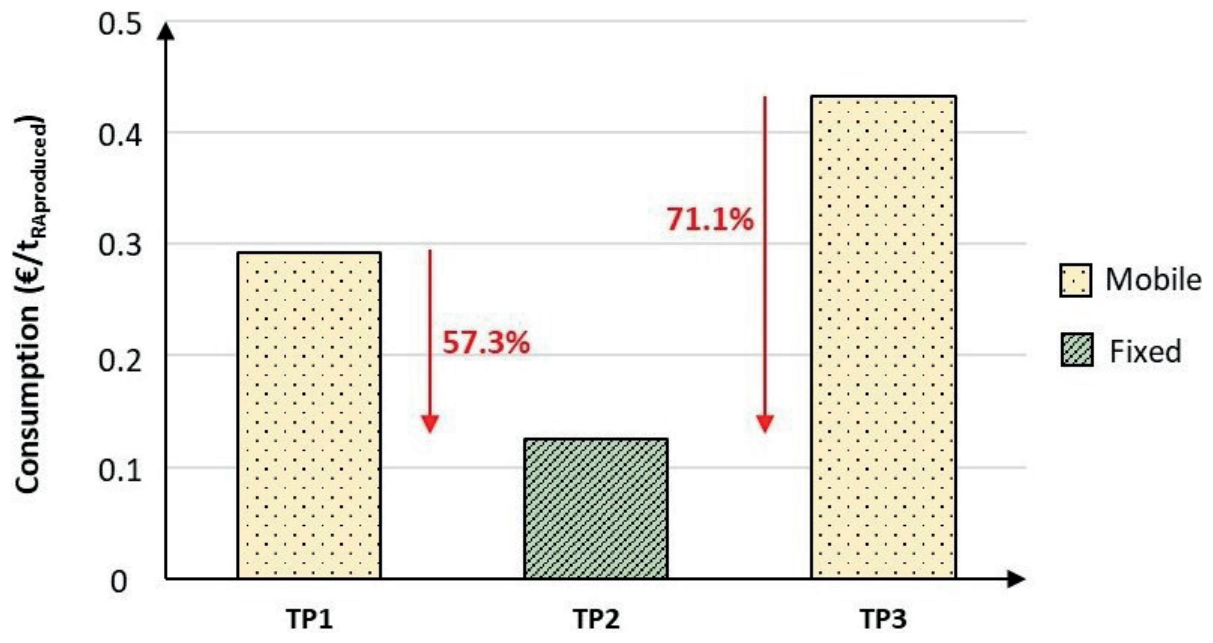

FIGURE 6: TP consumption per tonne of RAs produced.

properties) of both CDWs and RAs based on the quality control procedures carried out upstream and downstream of the treatment processes, as described above.

In this paper, as stated before, technical, chemical and leaching properties have been discussed in tabular format but the release of contaminants was also discussed by analyzing, with the box and violin plot methodology, the $\mathrm{pH}$ and total chromium.

\subsubsection{Chemical properties}

Table 6 shows the chemical composition of CDWs and RAs. Data obtained from the chemical certificates were reported on an average, minimum and maximum value basis and compared to the contamination threshold concentrations (CSC) listed in column A "green public areas and sites for residential use" and column B "commercial and industrial sites" of Table 1 of the L.D 152/2006.

According to Chen \& Zhou (2020), the pH of CDWs is generally alkaline, with an average value of 8.5 and a maximum value of about 12 . The highest $\mathrm{pH}$ values were mainly detected in EWC 170101 and EWC 170904 which have an intrinsically high content of cement. Aluminium is the most abundant element both in CDWs and RAs with an average content of $15.65 \mathrm{~g} / \mathrm{kg}$ TS and $9.44 \mathrm{~g} / \mathrm{kg}$ TS, respectively. These results agree with the data published by Butera et al. (2014) who detected a high aluminum content in CDWs equal to about $40 \mathrm{~g} / \mathrm{kg}$ TS.

As regards CDWs, manganese and sulphates are minor non-critical elements with an average content of $831.7 \mathrm{mg} /$ $\mathrm{kg}$ TS and $89.63 \mathrm{mg} / \mathrm{kg}$ TS, respectively. Mercury, tin and thallium are critical elements for the use in public and residential sites (average contents higher than $1 \mathrm{mg} / \mathrm{kg} \mathrm{TS}$ ), together with beryllium which showed an average content higher than $2 \mathrm{mg} / \mathrm{kg}$ TS. In particular, the maximum content of these elements was found in EWC 170904.

Total chromium, nickel, lead, copper, vanadium, and zinc are not critical parameters in terms of average concentrations, but the detected maximum values (between 350 and $5,300 \mathrm{mg} / \mathrm{kg} \mathrm{TS}$ ) are higher than the regulatory limits imposed by both column A and B of L.D. 152/2006.
In particular, maximum values of total chromium and copper were detected in EWC 170904, while maximum values of nickel, lead, vanadium and zinc were detected in EWC 170504.

BTEX hydrocarbons (sum of benzene, toluene, ethylbenzene and xylene) are present in an average total concentration equal to $2.04 \mathrm{mg} / \mathrm{kg}$ TS exceeding the limit of column A (1.6 mg/kg TS). Specifically, benzene and xylene, with an average content of $0.53 \mathrm{mg} / \mathrm{kg}$ TS and $0.55 \mathrm{mg} / \mathrm{kg}$ TS respectively, are the critical compounds.

PCBs were detected in higher concentrations (range 0-3 $\mathrm{mg} / \mathrm{kg}$ TS) than the regulatory limit of column A equal to $0.06 \mathrm{mg} / \mathrm{kg}$ TS. The light and heavy hydrocarbons content averaged $10 \mathrm{mg} / \mathrm{kg}$ TS and $850 \mathrm{mg} / \mathrm{kg}$ TS respectively and were above the regulatory limits of column $A$ and B. In particular, the maximum value of heavy hydrocarbon (345,000 mg/kg TS) was detected in EWC 170302 "bituminus mixtures".

Regarding RAs, tin and benzene are the only critical elements with an average content higher than $1 \mathrm{mg} / \mathrm{kg}$ TS and $0.1 \mathrm{mg} / \mathrm{kg}$ TS (limits of column A), respectively.

For both CDWs and RAs, arsenic, antimony, barium, cadmium and selenium are present in average concentrations between 0.5 and $70 \mathrm{mg} / \mathrm{kg} \mathrm{TS}$, below the regulatory limits.

\subsubsection{Leaching behaviour}

As previously mentioned, the leaching behavior of CDWs and RAs was evaluated according to the compliance test imposed by UNI EN 12457-2 and compared with the regulatory limits of M.D. 186/2006 for unbound recovery. As for the chemical composition, the data obtained from leaching certificates were reported on an average, minimum and maximum value basis.

Comparing the CDW average leaching concentrations to the legal limits, mercury is the only critical parameter with an average concentration greater than $1 \mu \mathrm{g} / \mathrm{L}$ (Table 7). At the same time, the average concentrations of all the other parameters comply with the regulatory limits for both CDWs and RAs. Differently, the maximum values of 
TABLE 6: Chemical composition of CDWs and RAs (pollutant contents reported in the average and minimum-maximum range) (TS: total solid).

\begin{tabular}{|c|c|c|c|c|c|c|c|c|c|}
\hline \multirow[t]{2}{*}{ Parameters } & \multirow[t]{2}{*}{ U.M. } & \multicolumn{3}{|c|}{ CDWs } & \multicolumn{3}{|c|}{ RAs } & \multicolumn{2}{|c|}{$\begin{array}{l}\text { Limit values } \\
\text { (L.D. 152/2006) }\end{array}$} \\
\hline & & Min & Max & Mean & Min & Max & Mean & Column A & Column B \\
\hline $\mathrm{pH}$ & - & 2.90 & 11.95 & 8.43 & - & - & - & - & - \\
\hline Dry residue at $105^{\circ} \mathrm{C}$ & $(\%)$ & 19.90 & 100 & 93.70 & 83.10 & 99.70 & 95.87 & - & - \\
\hline Aluminum & $(\mathrm{mg} / \mathrm{kg} \mathrm{TS})$ & 83.90 & 57248 & 15651.8 & 0.00 & 9442 & 9442 & - & - \\
\hline Antimony & $(\mathrm{mg} / \mathrm{kg} \mathrm{TS})$ & 0.01 & 102.48 & 5.05 & 0.30 & 10 & 2.55 & 10 & 30 \\
\hline Arsenic & $(\mathrm{mg} / \mathrm{kg} \mathrm{TS})$ & 0.05 & 82.90 & 8.25 & 0.30 & 15 & 6.91 & 20 & 50 \\
\hline Barium & (mg/kg TS) & 1 & 482.50 & 65.86 & - & - & - & - & - \\
\hline Beryllium & (mg/kg TS) & 0.01 & 20 & 2.20 & 0.20 & 10 & 1.13 & 2 & 10 \\
\hline Cadmium & $(\mathrm{mg} / \mathrm{kg} \mathrm{TS})$ & 0.01 & 22.60 & 1.89 & 0.10 & 10 & 0.42 & 2 & 15 \\
\hline Cobalt & $(\mathrm{mg} / \mathrm{kg} \mathrm{TS})$ & 0.02 & 105 & 6.23 & 0.50 & 10 & 2.25 & 20 & 250 \\
\hline Total chromium & $(\mathrm{mg} / \mathrm{kg} \mathrm{TS})$ & 0.10 & 7410.20 & 53.49 & 1.00 & 187.40 & 31.90 & 150 & 800 \\
\hline Exavalent chromium & $(\mathrm{mg} / \mathrm{kg} \mathrm{TS})$ & 0.10 & 50 & 1.73 & 0.10 & 10 & 0.34 & 2 & 15 \\
\hline Mercury & $(\mathrm{mg} / \mathrm{kg} \mathrm{TS})$ & 0 & 20 & 1.55 & 0.10 & 10 & 0.37 & 1 & 5 \\
\hline Molybdenum & $(\mathrm{mg} / \mathrm{kg} \mathrm{TS})$ & 0.10 & 20 & 1.69 & - & - & - & - & - \\
\hline Nickel & $(\mathrm{mg} / \mathrm{kg} \mathrm{TS})$ & 0.10 & 851 & 20.95 & 1 & 84.9 & 15.94 & 120 & 500 \\
\hline Lead & $(\mathrm{mg} / \mathrm{kg} \mathrm{TS})$ & 0.10 & 1589 & 43.90 & 6 & 98.66 & 37.57 & 100 & 1000 \\
\hline Copper & $(\mathrm{mg} / \mathrm{kg} \mathrm{TS})$ & 1 & 1490 & 37.71 & 1 & 100 & 34.73 & 120 & 600 \\
\hline Selenium & $(\mathrm{mg} / \mathrm{kg} \mathrm{TS})$ & 0 & 20 & 1.33 & 0.30 & 2.40 & 0.79 & 3 & 15 \\
\hline Tin & (mg/kg TS) & 0.01 & 51.67 & 3.66 & 0.45 & 10 & 1.37 & 1 & 350 \\
\hline Thallium & $(\mathrm{mg} / \mathrm{kg} \mathrm{TS})$ & 0.01 & 20 & 1.66 & 0.50 & 1 & 0.96 & 1 & 10 \\
\hline Tellurium & (mg/kg TS) & 0.05 & 10 & 2.00 & - & - & - & - & - \\
\hline Vanadium & $(\mathrm{mg} / \mathrm{kg} \mathrm{TS})$ & 0.5 & 355.80 & 67.72 & 0 & 39 & 19.20 & 90 & 250 \\
\hline Zinc & $(\mathrm{mg} / \mathrm{kg} \mathrm{TS})$ & 1 & 5288 & 109.75 & 13.90 & 145 & 81.67 & 150 & 1500 \\
\hline Manganese & $(\mathrm{mg} / \mathrm{kg} \mathrm{TS})$ & 0.10 & 2010 & 831.70 & - & - & - & - & - \\
\hline Cyanide & (mg/kg TS) & 0.02 & 2 & 0.89 & 1 & 1 & 1.00 & 1 & 100 \\
\hline Sulfates & $(\mathrm{mg} / \mathrm{kg} \mathrm{TS})$ & 5 & 160 & 89.83 & - & - & - & - & - \\
\hline Nitrates & (mg/kg TS) & 1.40 & 54 & 15.78 & - & - & - & - & - \\
\hline Chlorides & $(\mathrm{mg} / \mathrm{kg} \mathrm{TS})$ & 5.10 & 52.50 & 15.78 & - & - & - & - & - \\
\hline Benzene & $(\mathrm{mg} / \mathrm{kg} \mathrm{TS})$ & 0.003 & 10 & 0.53 & 0.01 & 0.02 & 0.19 & 0.10 & 2 \\
\hline Ethylbenzene & (mg/kg TS) & 0.003 & 10 & 0.48 & 0.01 & 0.02 & 0.19 & 0.50 & 50 \\
\hline Toluene & (mg/kg TS) & 0.003 & 10 & 0.48 & 0.01 & 0.02 & 0.19 & 0.50 & 50 \\
\hline Xylene & (mg/kg TS) & 0.003 & 10 & 0.55 & 0.01 & 0.02 & 0.19 & 0.50 & 50 \\
\hline PAHs & $(\mathrm{mg} / \mathrm{kg} \mathrm{TS})$ & 0.00865 & 10 & 0.75 & 0.01 & 1 & 0.09 & 10 & 100 \\
\hline PCBs & $(\mathrm{mg} / \mathrm{kg} \mathrm{TS})$ & 0 & 2.77 & 0.45 & 0.01 & 0.01 & 0.01 & 0.06 & 5 \\
\hline Light hydrocarbons $(\mathrm{C} \leq 12)$ & $(\mathrm{mg} / \mathrm{kg} \mathrm{TS})$ & 0.01 & 285.20 & 10.22 & - & - & - & 10 & 250 \\
\hline Heavy hydrocarbons $(C \geq 12)$ & (mg/kg TS) & 0.50 & 345000 & 850.65 & 10 & 101 & 26.36 & 50 & 750 \\
\hline Hydrocarbons C10-C40 & $(\mathrm{mg} / \mathrm{kg} \mathrm{TS})$ & 1 & 19583 & 218.82 & 20 & 20 & 20.00 & - & - \\
\hline Asbestos & $(\mathrm{mg} / \mathrm{kg} \mathrm{TS})$ & 0 & $<1000$ & 343.65 & $<100$ & $<1000$ & 118.37 & 1000 & 1000 \\
\hline
\end{tabular}

released contaminants often do not comply with the regulatory limits. In fact, nitrates, sulphates, copper, total chromium, lead, selenium, mercury, and COD were detected in higher concentrations than the limits imposed by M.D. 186/2006 in both CDWs and RAs.

Higher maximum concentrations of fluorides, chlorides, nickel, vanadium, and cadmium were also detected in CDWs.
Figure 7 shows the results of the statistical analysis developed on $\mathrm{pH}$ and total chromium. The analysis was performed by evaluating: (a) the release of contaminants from CDWs and RAs and (b) the release of contaminants according to the three selected EWC codes (EWC 170101, EWC 170504 and EWC 170904). In order to identify the critical pollutants for recovery and final use, the variability range of pollutant concentrations was assessed and com- 
TABLE 7: Leaching behaviour of CDWs and RAs (pollutant releases reported in the average and minimum-maximum range).

\begin{tabular}{|c|c|c|c|c|c|c|c|c|}
\hline \multirow{2}{*}{ Parameters } & \multirow{2}{*}{ U.M. } & \multicolumn{3}{|c|}{ CDWs } & \multicolumn{3}{|c|}{ RAs } & \multirow{2}{*}{$\begin{array}{c}\text { Limit } \\
\text { values (M.D. } \\
\text { 186/2006) }\end{array}$} \\
\hline & & Min & Max & Mean & Min & Max & Mean & \\
\hline $\mathrm{pH}$ & - & 2.20 & 12.20 & 8.61 & 7.03 & 12 & 8.89 & $5.5-12$ \\
\hline Nitrates & $(\mathrm{mg} / \mathrm{L})$ & 0.05 & 95.20 & 5.09 & 0.10 & 73.30 & 10.28 & 50 \\
\hline Fluorides & $(\mathrm{mg} / \mathrm{L})$ & 0.01 & 7.50 & 0.44 & 0.01 & 1.21 & 0.27 & 1.5 \\
\hline Sulphates & $(\mathrm{mg} / \mathrm{L})$ & 0.40 & 1613 & 103.47 & 1 & 615 & 55.76 & 250 \\
\hline Chlorides & $(\mathrm{mg} / \mathrm{L})$ & 0.08 & 531 & 14.93 & 1 & 57.70 & 10.99 & 100 \\
\hline Cyanide & $(\mu \mathrm{g} / \mathrm{L})$ & 0 & 50 & 10.72 & 0.05 & 50 & 13.77 & 50 \\
\hline Barium & $(\mathrm{mg} / \mathrm{L})$ & 0 & 1 & 0.09 & 0.01 & 0.50 & 0.08 & 1 \\
\hline Copper & $(\mathrm{mg} / \mathrm{L})$ & 0 & 0.22 & 0.01 & 0.0002 & 1 & 0.02 & 0.05 \\
\hline Zinc & $(\mathrm{mg} / \mathrm{L})$ & 0.0001 & 2.80 & 0.17 & 0.001 & 1.64 & 0.12 & 3 \\
\hline Berillium & $(\mu \mathrm{g} / \mathrm{L})$ & 0 & 10 & 1.70 & 0.10 & 10 & 2.23 & 10 \\
\hline Cobalt & $(\mu \mathrm{g} / \mathrm{L})$ & 0 & 67 & 5.67 & 0.10 & 30 & 5.49 & 250 \\
\hline Nickel & $(\mu \mathrm{g} / \mathrm{L})$ & 0.01 & 190 & 6.47 & 0.10 & 10 & 3.82 & 10 \\
\hline Vanadium & $(\mu \mathrm{g} / \mathrm{L})$ & 0 & 643.50 & 20.20 & 0.015 & 94 & 15.52 & 250 \\
\hline Arsenic & $(\mu \mathrm{g} / \mathrm{L})$ & 0.12 & 0.13 & 7.55 & 0.10 & 41 & 5.63 & 50 \\
\hline Cadmium & $(\mu \mathrm{g} / \mathrm{L})$ & 0 & 10 & 1.36 & 0.10 & 5 & 1.95 & 5 \\
\hline Total chromium & $(\mu \mathrm{g} / \mathrm{L})$ & 0.01 & 1361 & 19.83 & 1 & 183 & 18.97 & 50 \\
\hline Lead & $(\mu \mathrm{g} / \mathrm{L})$ & 0.02 & 5111 & 32.97 & 0.10 & 79 & 5.76 & 50 \\
\hline Selenium & $(\mu \mathrm{g} / \mathrm{L})$ & 0 & 84 & 3.99 & 0.10 & 10 & 3.85 & 10 \\
\hline Mercury & $(\mu \mathrm{g} / \mathrm{L})$ & 0 & 50 & 1.01 & 0.10 & 1.62 & 0.60 & 1 \\
\hline Asbestos & $(\mathrm{mg} / \mathrm{L})$ & 0 & 30 & 3.98 & 0 & 30 & 2.61 & 30 \\
\hline COD & $(\mathrm{mg} / \mathrm{L})$ & 1 & 443 & 25.48 & 5 & 43.30 & 18.35 & 30 \\
\hline
\end{tabular}

pared with the regulatory limits.

According to the box-plot results, the $\mathrm{pH}$ of both CDWs and RAs was generally alkaline with $50 \%$ of values ranging from 7.5 to 10 . As shown by the violin plots (Figure 8), which reproduce the real distribution of data density, the $\mathrm{pH}$ values showed a peak also in the range from 11 to over 12 , slightly exceeding the national regulatory limit.

As recently studies reported (Coudray et al., 2017; Gupta et al., 2018; Ng \& Engelsen, 2018; Saca et al., 2017), this strong alkalinity is mainly due to the cement and concrete fractions contained in both CDWs and RAs. In agreement with these considerations, as shown in Figure 7 (b), EWC 170101 "cement" had the highest $\mathrm{pH}$ values with a median of 11.3 and highly left-skewed data.

Lower $\mathrm{pH}$ values were observed for mixed CDWs (EWC 170904) and soil and stones (EWC 170504) leachates (median values of 8.78 and 8.11 respectively). As stated by Butera et al. (2014) this could be ascribed to the presence of bricks and soil in the sample mixtures.

Total chromium is generally one of the critical compounds in CDW and RA leachates (Butera et al., 2014; Del Rey et al., 2015; Delay et al., 2007; Maia et al., 2018). According to the box and violin plot results, the highest chromium release was found in RAs in the range of $2.5-62.5$ $\mu \mathrm{g} / \mathrm{L}$, exceeding the regulatory limit. As for the $\mathrm{pH}$, the high chromium release was mainly due to the cement fractions contained in EWC 170101, in which over $50 \%$ of the total concentrations exceeded the recovery limit of $50 \mu \mathrm{g} / \mathrm{L}$. On the other hand, as Galvín et al. (2014); Zhang et al. (2018) exposed, chromium has high leachability at alkaline $\mathrm{pH}$ $(\mathrm{pH}>10)$, which confirms the higher release compared to soil and stones (EWC 170504) and mixed CDWs (EWC 170904).

\subsubsection{Technical performance of RAs}

Table 8 reports the technical properties of RAs produced by the 3 treatment plants. As mentioned above, data refer to the EC marking tests performed on RAs (fine, medium and coarse) according to UNI EN 13242 for their use in civil engineering work and road construction.

According to the results, the RA particle density ranges from $2150 \mathrm{~kg} / \mathrm{m}^{3}$ to $2810 \mathrm{~kg} / \mathrm{m}^{3}$, with an average value of $2480 \mathrm{~kg} / \mathrm{m}^{3}$. In particular, the highest density values were detected in coarse RAs. In terms of resistance to fragmentation (Los Angeles), the values range from 29 to 40 . Compared to natural aggregates, RAs are similar to friable rocks. Regarding water absorption (WA), WA of coarse recycled aggregates varies between $0.6 \%$ and $7 \%$, while WA of fine RAs can reach values up to $9.6 \%$. These data confirm the results obtained by other authors (Vieira et al., 2016). Finally, water-soluble chloride and acid-soluble sulphates show average concentrations of $0.066 \%$ and $0.4 \%$, respectively.

\subsection{Barriers and possible strategies for CDW recov- ery}

Based on the analysis developed, this study has investigated the barriers to CDW recovery and the possible 

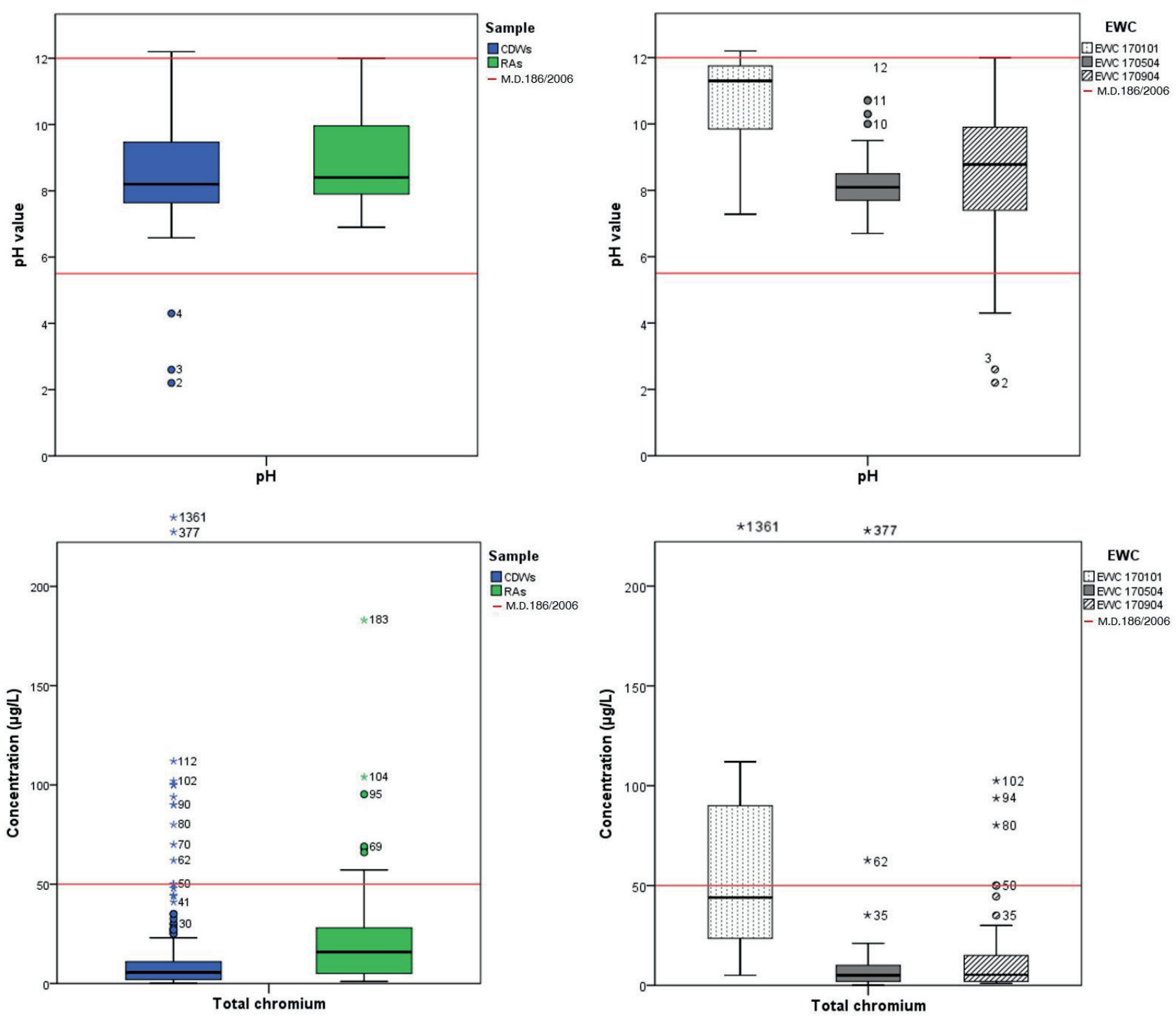

(a)

(b)

FIGURE 7: CDW treatment flow sheet.

strategies to overcome these hurdles. As shown in Figure 9, the main barriers identified are classified into 3 categories: economic, logistical/technical and regulatory/cultural.

The main obstacle concerns the propensity of end users to use, for high-grade applications, natural aggregates (cheaper and with high technical-environmental performance) rather than RAs which "derive from wastes". The lack of consumer awareness and consequently the commercial disadvantage for companies is therefore the main obstacle to recovery. In this context, the absence of a market demand for good quality RAs (e.g. RCAs) directs recycling plants to produce only mixed recycled aggregates. Thus, the implementation of advanced treatment technologies is not performed since the economic costs are too high and are not compensated by the market demand. This hurdle is recognized as a "not foreseen market opportunities" for which the company does not yet identify any added-value in further qualifying their products and services. Furthermore, in the regional and national territory, there are no economic incentives for recycling plants.

In terms of logistical and technical hurdles, also the sampling procedure prescribed by the EN 10802 for the evaluation of the RA leaching behaviour is considered not representative, as directly confirmed by companies. In particular, the quantity of sampled material, equal to a few grams, can not be considered representative of the heaps consisting of thousands of $\mathrm{m}^{3}$. Similarly, the leaching test method defined by UNI EN 12457-2, which requires a maximum particles diameter equal to $4 \mathrm{~mm}$, is not considered representative of the real RA use conditions (diameter $>4 \mathrm{~mm}$ ).

To overcome these barriers, governmental and scientific research involvement are necessary to improve CDW recovery and RA end-use. Here, some levels for change are identified:

- Economic and policy instruments: increased recycling could be achieved by economically viable measures to improve waste management. In particular, the compet- 

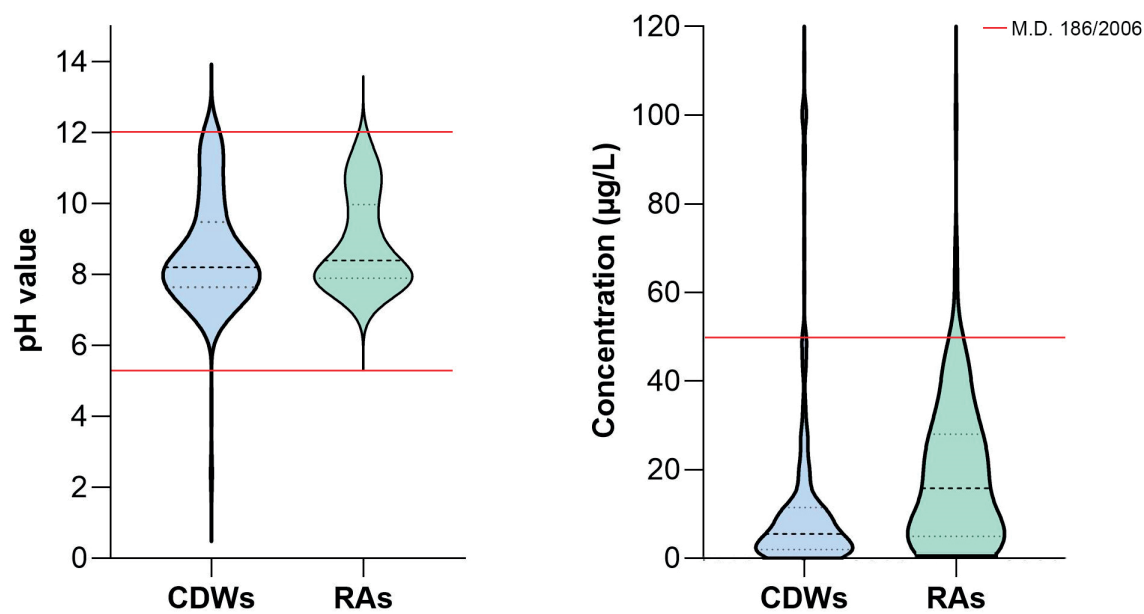

FIGURE 8: Statistical analysis: violin plots of pollutant concentrations ( $\mathrm{pH}$ and total chromium) in CDWs and RAs.

itiveness of recycled materials could be increased by raising the price of natural aggregates and taxing the mining activity. In addition, economic incentives (tax credit) should be provided by national authorities for companies who produce recycled products.

- Education policies: recycled materials derived from wastes are still perceived to be inferior to natural ones. Policy interventions that spread awareness and knowledge of these new materials are therefore essential. In particular, public information and education campaigns should be launched and best practice should be promoted in order to clarify that the technical and environmental performances are comparable to those of natural aggregates. These actions would stimulate the market demand for RAs, even of better quality.
Improvement of technologies: as above-mentioned, the increase in the use of recycled aggregates depends on their ability to be competitive with virgin raw materials in terms of both cost and quality. Enhancing the treatment process by implementing new advanced technologies may increase costs but the greater confidence in the use of RAs and the consequent market demand would allow to offset these costs. The research and development policies may impact the improvement of developed technologies and recycled materials produced. In particular, in the case studies analyzed, the commitment of the three companies is to evaluate the use of RCAs for more noble applications (i.e. concrete production). To achieve and promote this, they have launched research activities in collaboration with the

TABLE 8: Technical properties of RAs produced by the 3 TPs (values reported in the average and minimum-maximum range).

\begin{tabular}{|c|c|c|c|c|c|c|c|c|c|c|c|c|c|}
\hline \multirow{2}{*}{ Property } & \multirow{2}{*}{ U.M. } & \multicolumn{3}{|c|}{ RA } & \multicolumn{3}{|c|}{$\mathbf{R A} \mathbf{A}_{\text {fine }}$} & \multicolumn{3}{|c|}{$\mathbf{R A}_{\text {medium }}$} & \multicolumn{3}{|c|}{$\mathbf{R A}_{\text {coarse }}$} \\
\hline & & Min & Max & Mean & Min & Max & Mean & Min & Max & Mean & Min & Max & Mean \\
\hline Particle size & $\mathrm{d} / \mathrm{D}$ & 0 & 180 & - & 0 & 10 & - & 0 & 31 & - & 0 & 180 & - \\
\hline Flakiness index & $\mathrm{FI}$ & 18 & 35 & 27 & - & - & - & - & - & - & 18 & 35 & 27 \\
\hline Shape index & $\mathrm{SI}$ & 20 & 40 & 30 & - & - & - & 20 & 40 & 30 & 20 & 40 & 30 \\
\hline Fines content & $f$ & 2 & 9 & 6 & 3 & 3 & 3 & 3 & 3 & 3 & 2 & 9 & 6 \\
\hline Sand equivalent value & SE & 20 & 85 & 53 & 47 & 85 & 66 & 48 & 48 & 48 & 20 & 46 & 33 \\
\hline Methylene blue test & $\mathrm{MB}$ & 0 & 4 & 2 & 0.3 & 0.6 & 0.5 & - & - & - & 2 & 3.9 & 3 \\
\hline Particle density & $\mathrm{kg} / \mathrm{m}^{3}$ & 2150 & 2810 & 2480 & 2150 & 2790 & 2470 & 2291 & 2756 & 2524 & 2282 & 2810 & 2546 \\
\hline Bulk density & $\mathrm{kg} / \mathrm{m}^{3}$ & 2321 & 2940 & 2631 & 2350 & 2786 & 2568 & 2446 & 2840 & 2643 & 2321 & 2940 & 2631 \\
\hline Los Angeles coefficient & LA & 29 & 40 & 35 & - & - & - & 29 & 35 & 32 & 29 & 40 & 35 \\
\hline Micro-Deval coefficient & MDE & 35 & 41 & 38 & - & - & - & - & - & - & 35 & 41 & 38 \\
\hline Water absorption & $\% W A$ & 0.4 & 9.6 & 5 & 1 & 9.6 & 5 & 0.4 & 5.3 & 3 & 0.6 & 7 & 4 \\
\hline Freeze/thaw resistance & $\mathrm{F}$ & 1 & 22 & 12 & 1 & 1 & 1 & - & - & - & 10 & 22 & 16 \\
\hline Alkali-silica reactivity & - & \multicolumn{3}{|c|}{ Non-reactive } & \multicolumn{3}{|c|}{ Non-reactive } & \multicolumn{3}{|c|}{ Non-reactive } & \multicolumn{3}{|c|}{ Non-reactive } \\
\hline Water-soluble chloride & $\%$ & 0.0018 & 0.01 & 0.006 & 0.006 & 0.006 & 0.006 & 0.0018 & 0.01 & 0.006 & - & - & - \\
\hline Acid-soluble sulphate & AS & 0.01 & 0.8 & 0.4 & 0.2 & 0.2 & 0.2 & 0.01 & 0.2 & 0.1 & 0.036 & 0.8 & 0.4 \\
\hline Total sulfur & $\mathrm{S}$ & 0.01 & 1 & 0.5 & 0.01 & 1 & 0.5 & 0.01 & 1 & 0.5 & 0.14 & 1 & 0.6 \\
\hline
\end{tabular}




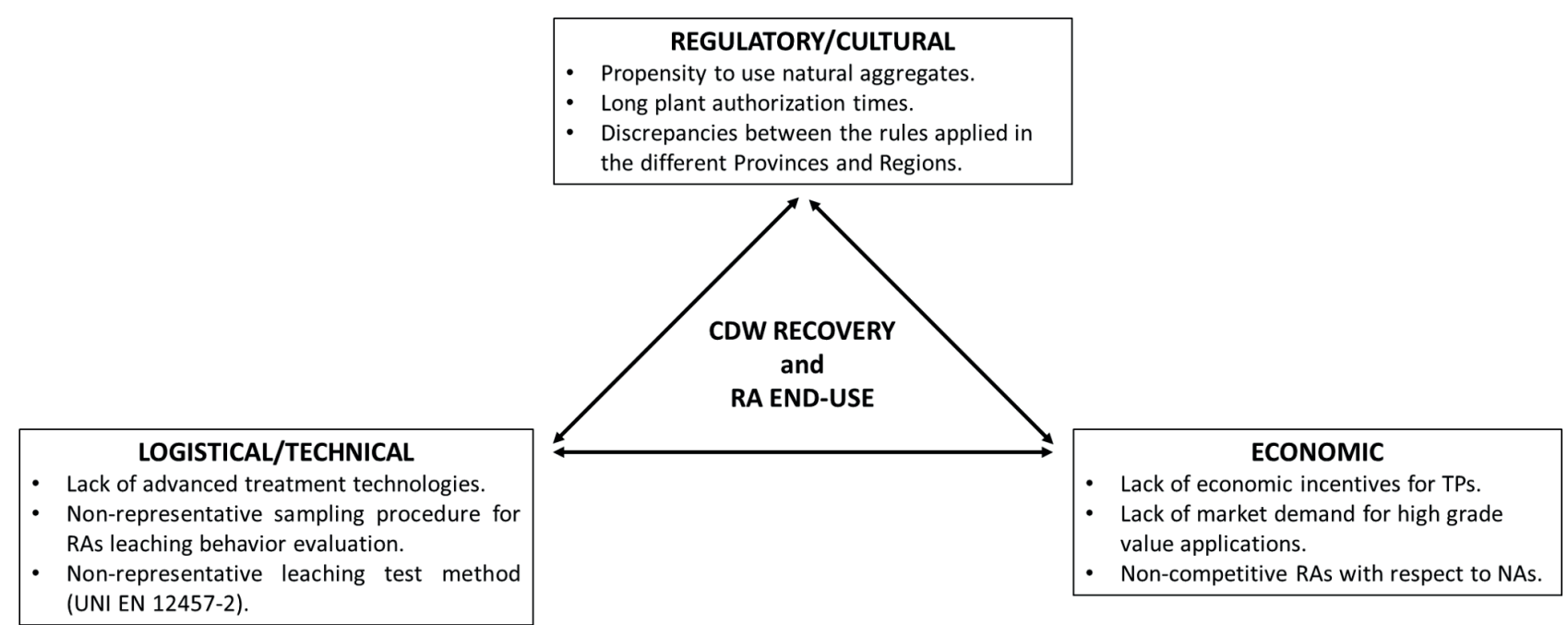

FIGURE 9: Barriers to CDWs recovery.

university to experimentally investigate the feasibility of RCAs use.

- Research activities: development of targeted research activities that re-evaluate the sampling methods and simulate the release of pollutants from RAs in conditions of on-site use (i.e. without altering the grain size).

\section{CONCLUSIONS}

In this study, the management and operational data of three CDW treatment plants located in the Province of Brescia (the Lombardy Region) were analyzed. The aim of the study was to understand and define the current CDW treatment chains adopted in the Region in order to highlight barriers that still limit CDW recovery and possible strategies to overcome these hurdles.

The following conclusions can be drawn as a result of the research:

- EWC 170904, EWC 170504 and EWC 170101 are the most managed CDW flows in the area. In particular, $50 \%-80 \%$ of the CDWs managed is represented by EWC 170904.

- Instead, EWC 170504 and EWC 170101 represent approximately $11 \%-36 \%$ and $7 \%-14 \%$ of the total CDWs managed.

- The average recovery efficiency of the treatment plants is strongly related to the technology adopted by the plants. The fixed plant, equipped with performing technologies, has the highest recovery efficiency of $95 \%$. Instead, the mobile plants, equipped with less performing technologies, have lower efficiencies of $62 \%$ and $70 \%$, respectively.

CDW treatment plants are located in natural aggregate excavation quarries which, over time, have adapted their work sites and technologies to the treatment and recovery of CDWs. The treatment techniques applied, are in fact borrowed from those already used to produce natural aggregates and consist of technologically interconnected phases of crushing, separation of ferrous metals and unwanted materials and dry sieving. The MRAs produced are of medium-low quality and are mostly used in road and geotechnical applications. In order to obtain high quality RAs, which can be used for high value applications, the selective demolition and the improvement of source separation is highly recommended. Upstream of the construction process, it is also essential to encourage the eco-design of products, in order to promote the industrialization of disassembly, the separation of single components and the recycling of endof-life materials. Moreover, the current treatment technology implementation (e.g. washing systems for salt removal such as sulphates and chlorides, air classifiers for lighter fraction removal) through economic incentives provided to CDW treatment plants would allow for more efficient recycling and higher quality recycled materials.

Finally, to evaluate the potentially critical parameters for recovery and final use, the study included an analysis of the chemical and leaching properties of both CDWs and RAs.

The chemical composition results show that the $\mathrm{pH}$ of CDWs is generally alkaline and alluminium is the most abundant element both in CDWs and RAs. Comparing the average chemical contents to the legal limits of L.D. $152 / 2006$, tin and benzene are the most critical elements for both CDWs and RAs with average contents higher than the limits of column A.

Comparing the leaching results with regulatory limit values of M.D. 186/2006 led to the following conclusions:

- the CDW and RA pH is generally alkaline and mainly related to the cement and concrete fractions contained in EWC 170101;

- mercury was identified as a critical compound in CDW leachates;

- total chromium was identified as a critical element both in CDWs (EWC 170101) and RAs in comparison with available regulatory limits. Also sulphates, with a maximum concentration of over $1600 \mathrm{mg} / \mathrm{L}$, were identified as a critical parameter in CDWs and mainly releated to ceramic fractions contained in EWC 170904. 
In this context, as emerged from the analysis developed, the environmental compatibility of these materials should be evaluated by adopting sampling procedures representative of the real quantities of materials analyzed (heaps of thousands of cubic meters) and leaching test methods representative of the real RA use conditions ( $d>4 \mathrm{~mm})$.

\section{AKNOWLEDGEMENTS}

This work is developed within the $\mathrm{PhD}$ research project "Environmental and technical characterization of construction and demolition wastes and recycled aggregates for their use in concrete, road construction and geotechnical applications", financed by the companies Gruppo Gatti S.p.A, Esse Emme S.r.l., and Fasanini S.r.l., located in Brescia, Italy. The authors wish to thank these companies for their availability during the research work development and their technical support during data collection and CDW treatment chain analyses. We also thank the Italian National Builders' Association (ANCE Lombardy) and the National Association of Recycled Aggregate Producers (ANPAR) for their willingness to provide us with their chemical and leaching data for the statistical analysis.

\section{REFERENCES}

Altamura, P. (2015). Costruire a zero rifiuti. Strategie e strumenti per la prevenzione e l'upcycling dei materiali di scarto in edilizia - FrancoAngeli. https://www.francoangeli.it/Ricerca/scheda_libro.aspx?ld=22925

Barbudo, A., Galvín, A. P., Agrela, F., Ayuso, J., \& Jiménez, J. R. (2012). Correlation analysis between sulphate content and leaching of sulphates in recycled aggregates from construction and demolition wastes. Waste Management, 32(6), 1229-1235. https://doi. org/10.1016/j.wasman.2012.02.005

Bianchini, G., Ristovski, I., Milcov, I., Zupac, A., Natali, C., Salani, G. M., Marchina, C., Brombin, V., \& Ferraboschi, A. (2020). Chemical characterisation of construction and demolitionwaste in Skopje city and its surroundings (Republic of Macedonia). Sustainability (Switzerland), 12(5). https://doi.org/10.3390/su12052055

Borghi, G., Pantini, S., \& Rigamonti, L. (2018). Life cycle assessment of non-hazardous Construction and Demolition Waste (CDW) management in Lombardy Region (Italy). Journal of Cleaner Production, 184, 815-825. https://doi.org/10.1016/j.jclepro.2018.02.287

Butera, S., Christensen, T. H., \& Astrup, T. F. (2014). Composition and leaching of construction and demolition waste: Inorganic elements and organic compounds. Journal of Hazardous Materials. https://doi.org/10.1016/j.jhazmat.2014.05.033

Chen, Y., \& Zhou, Y. (2020). The contents and release behavior of heavy metals in construction and demolition waste used in freeway construction. Environmental Science and Pollution Research, 27(1), 1078-1086. https://doi.org/10.1007/s11356-019-07067-w

Coudray, C., Amant, V., Cantegrit, L., Le Bocq, A., Thery, F., Denot, A., \& Eisenlohr, L. (2017). Influence of Crushing Conditions on Recycled Concrete Aggregates (RCA) Leaching Behaviour. Waste and Biomass Valorization, 8(8), 2867-2880. https://doi.org/10.1007/ s12649-017-9868-2

Del Rey, I., Ayuso, J., Galvín, A. P., Jiménez, J. R., López, M., \& García-Garrido, M. L. (2015). Analysis of chromium and sulphate origins in construction recycled materials based on leaching test results. In Waste Management. https://doi.org/10.1016/j.wasman.2015.07.051

Delay, M., Lager, T., Schulz, H. D., \& Frimmel, F. H. (2007). Comparison of leaching tests to determine and quantify the release of inorganic contaminants in demolition waste. Waste Management, 27(2), 248-255. https://doi.org/10.1016/j.wasman.2006.01.013

European Commission. (2016). EU Construction and Demolition Waste Protocol and Guidelines - European Commission. http://ec.europa. eu/growth/content/eu-construction-and-demolition-waste-protocol-0_en
European Commission. (2017). Resource Efficient Use of Mixed Wastes - Improving management of construction and demolition waste (Issue September). https://doi.org/10.5772/46110

Eurostat, 2019. (2019). Statistics Database. https://ec.europa.eu/eurostat/web/environment/waste/database

Galvín, A. P., Agrela, F., Ayuso, J., Beltrán, M. G., \& Barbudo, A. (2014). Leaching assessment of concrete made of recycled coarse aggregate: Physical and environmental characterisation of aggregates and hardened concrete. Waste Management, 34(9), 1693-1704. https://doi.org/10.1016/j.wasman.2014.05.001

Galvín, Adela P., Ayuso, J., García, I., Jiménez, J. R., \& Gutiérrez, F. (2014). The effect of compaction on the leaching and pollutant emission time of recycled aggregates from construction and demolition waste. Journal of Cleaner Production. https://doi.org/10.1016/j. jclepro.2014.07.074

Giorgi, S., Lavagna, M., \& Campioli, A. (2018). Guidelines for Effective and Sustainable Recycling of Construction and Demolition Waste. In Designing Sustainable Technologies, Products and Policies (pp. 211-221). Springer International Publishing. https://doi. org/10.1007/978-3-319-66981-6_24

Goh, B. H. (2016). Smart cities as a solution for reducing urban waste and pollution. In Smart Cities as a Solution for Reducing Urban Waste and Pollution. IGI Global. https://doi.org/10.4018/978-15225-0302-6

Gupta, N., Kluge, M., Chadik, P. A., \& Townsend, T. G. (2018). Recycled concrete aggregate as road base: Leaching constituents and neutralization by soil Interactions and dilution. Waste Management, 72, 354-361. https://doi.org/10.1016/j.wasman.2017.11.018

ISPRA. (2019). Rapporto Rifiuti Speciali. www.isprambiente.gov.it

Legambiente. (2017). Rapporto cave. https://www.legambiente.it/ sites/default/files/docs/rapporto_cave_2017.pdf

Legislative Decree 152/2006. (2006). Legislative Decree 3 April 2006 n.152. Code on the Environment. https://www.gazzettaufficiale.it/ dettaglio/codici/materiaAmbientale

Lombardy Region. (2018). Studi e ricerche per un'economia circolare nel settore dei rifiuti da costruzione e demolizione.

López-Uceda, A., Galvín, A. P., Barbudo, A., \& Ayuso, J. (2019). Longterm leaching and mechanical behaviour at recycled aggregate with different gypsum contents. Environmental Science and Pollution Research, 26(35), 35565-35573. https://doi.org/10.1007/ s11356-019-04925-5

Maia, M. B., De Brito, J., Martins, I. M., \& Silvestre, J. D. (2018). Toxicity of Recycled Concrete Aggregates: Review on Leaching Tests. The Open Construction and Building Technology Journal, 12(1), 187196. https://doi.org/10.2174/1874836801812010187

Ministerial Decree 186/2006. (2006). Ministerial Decree 04/05/2006 n.186. Regolamento recante modifiche al Decreto Ministeriale 5 Febbraio 1998 "Individuazione dei rifiuti non pericolosi sottoposti alle procedure semplificate di recupero, ai sensi degli articoli 31 e 33 del Decreto Legislati.

Ng, S., \& Engelsen, C. J. (2018). Construction and demolition wastes. In Waste and Supplementary Cementitious Materials in Concrete: Characterisation, Properties and Applications (pp. 229-255). Elsevier. https://doi.org/10.1016/B978-0-08-102156-9.00008-0

Pantini, S., Giurato, M., \& Rigamonti, L. (2019). A LCA study to investigate resource-efficient strategies for managing post-consumer gypsum waste in Lombardy region (Italy). Resources, Conservation and Recycling, 147, 157-168. https://doi.org/10.1016/j.resconrec.2019.04.019

Pantini, Sara, \& Rigamonti, L. (2016). Evaluation of the mass balance of the construction and demolition waste management system in Lombardy Region, Italy. CRETE 2016 Conference Proceedings, 1-9.

Ruggeri, M., Pantini, S., \& Rigamonti, L. (2019). Assessing the impact of selective demolition techniques on C\&D waste management. IOP Conference Series Earth and Environmental Science. https://doi. org/10.1088/1755-1315/296/1/012005

Saca, N., Dimache, A., Radu, L. R., \& lancu, I. (2017). Leaching behavior of some demolition wastes. Journal of Material Cycles and Waste Management, 19(2), 623-630. https://doi.org/10.1007/s10163015-0459-7

Siddique, R., \& Cachim, P. (2018). Waste and Supplementary Cementitious Materials in Concrete: Characterisation ... - Rafat Siddique, Paulo Cachim - Google Libri (p. 640). https://books.google.it/ books?id=maRBDwAAQBAJ\&pg=PA232\&lpg=PA232\&dq=demolition+waste+composition+concrete+gypsum+wood\&source=bl\&ots=DYfthYOuOz\&sig=ACfU3U3EWtZBhu0pMjFoaXqrfpBGjQHrOA\&hl=it\&sa=X\&ved=2ahUKEwji8r7J38LqAhXuShUIHWOWAEcQ6AEwFHoECA4QAQ\#v=onepage\& 
Vieira, C. S., \& Pereira, P. M. (2018). Use of Mixed Construction and Demolition Recycled Materials in Geosynthetic Reinforced Embankments. Indian Geotechnical Journal, 48(2), 279-292. https:// doi.org/10.1007/s40098-017-0254-6

Vieira, T., Alves, A., de Brito, J., Correia, J. R., \& Silva, R. V. (2016). Durability-related performance of concrete containing fine recycled aggregates from crushed bricks and sanitary ware. Materials and Design, 90, 767-776. https://doi.org/10.1016/j.matdes.2015.11.023

Zhang, Y.-B., Chen, J.-N., Ginder-Vogol, M., \& Edil, T. B. (2018). Effect of $\mathrm{pH}$ and Grain Size on the Leaching Mechanism of Elements from Recycled Concrete Aggregate. In Proceedings of GeoShanghai 2018 International Conference: Geoenvironment and Geohazard (pp. 325-334). Springer Singapore. https://doi.org/10.1007/978981-13-0128-5_37 